\title{
eEmerald $\begin{aligned} & \text { Journal of Criminological } \\ & \text { Practice, Policy and }\end{aligned}$
}

\section{Splitting to Survive: Understanding Terrorist Group Fragmentation}

\begin{tabular}{|r|l|}
\hline Journal: & Journal of Criminological Research, Policy and Practice \\
\hline Manuscript ID & JCRPP-07-2016-0013.R2 \\
\hline Manuscript Type: & Research Paper \\
\hline Keywords: & Terrorism, Splits, Political Organisational Theory, Survival, Schism, Spoilers \\
\hline & \\
\hline
\end{tabular}

\footnotetext{
SCHOLARONE $^{\text {"x }}$

Manuscripts
} 
Splitting to Survive

\section{Introduction}

One need only look to Syria and Iraq to appreciate the importance of understanding the cause and effect of the splintering of terrorist and insurgent organisations. In his 2014 State of the Union address U.S. President Barack Obama reaffirmed his support for the Syrian opposition fighting against President Bashar al-Assad, as long as they rejected the 'agenda of terror networks' (Obama, 2014). However, this was a hesitant support. In the lead up to this statement both Obama and then Secretary of State Hillary Clinton had indicated that it was the fragmentation of the Syrian opposition which had delayed their stronger support (Pearlman, 2013). While the fragmentation of this opposition had a clear effect on foreign policy, the splintering of Iraqi insurgents was affecting troops on the ground from the moment they set foot in Iraq. Between 2003 and 2006, the beginning of coalition forces' operations in Iraq, it was identified that up to fifty-six Sunni insurgent groups were involved in politically violent attacks in Iraq (Hafez, 2007). This is before the similarly fragmented Shia insurgency is even taken into consideration. However, it is not just within Iraq and Syria that organisational division is having a significant effect on terrorist or insurgent groups. One can analyse any terrorist or insurgent movement across time or place and will invariably find that at some stage this group was either formed from or affected by an organisational split. From the history of divisions in Palestinian militants (Bueno de Mesquita, 2008) to the proliferation of splintering in Irish republicanism (Morrison, 2014) very few are immune from internal divisions. With the world's attention currently focusing on ISIS it is clear that while the group's beginnings may have benefitted from local commanders splitting from al Qaeda (Byman, 2016) with the group's recent expansion they too have recently been threatened by internal cleavages (Abi-Habib, 2015). However, Al Qaeda itself are once again best by schism. In July 2016 Jabhat al-Nusra severed its ties with the group (Coghlan and Evans, 2016), and rebranded themselves as Jabhat Fath al Sham (The Front for the Liberation of al Sham). This may appear to be a split in a terrorist group. But it would be more accurately described as the fragmentation of a terrorist coalition. This therefore requires a different form of analysis.

With the clear effect which the splintering and fragmentation of insurgent and terrorist groups has had it is pertinent that we not only acknowledge it, but that we strive to gain a better understanding of both the process of splits and its true effects. This is precisely what the proposed article aims to do. Through the analysis of the existing literature the present article argues for the development of a more concerted effort to understand the cause and effect of organisational fragmentation. In doing so it presents a political organisational approach to understanding organisational splits. Through the application of this approach it is proposed that, perhaps counter-intuitively, that an appreciation organisational survival may be the cornerstone needed in order to fully understand organisational fragmentation. The article begins by briefly outlining some of the current understanding of organisational splits. In doing so the analysis incorporates the findings of research from the analysis of splits in terrorist organisations as well as non-violent legal organisations. It is only by incorporating what we already know from other fields that we can gain a more complete understanding of terrorist organisations. This introduction is then followed by the analysis of the central role that organisational plays within organisational fragmentation. Within this analysis the traditional perception of organisational survival is replaced with a more nuanced understanding of the concept that goes beyond the maintenance of a unified and numerically strong membership. This analysis includes the proposal of three hypotheses on organisational split. For many outside of the area of terrorism studies the analysis and proposals presented here may be nothing new. However, it is proposed that it is essential that what we know already about human organisations from a variety of fields be applied to develop our understanding of terrorist groups. Therefore we must adapt and apply what we already know about non-violent and legal human organisations in order to fathom the intricacies of terrorist organisations. These hypotheses are developed and presented here with the hope that they will be appropriately tested in future research. 
Splitting to Survive

\section{Understanding Splits}

An appreciation of the fluidity of structural dynamics within terrorist groups can give us a greater insight into how they operate, survive and evolve. It is essential that we acknowledge that these groups, similar to any other human organisation, are not homogenous. Their organisational existence is defined by their aims and ideology. However, within the group there is not always the cohesiveness and togetherness that they would wish to portray. As with any other human organisation there are regular disagreements, factionalisation and in the most extreme circumstances a complete organisational split. Terrorist organisations split for a variety of reasons from proposed politicisation to strategic changes, negotiated settlements to personality clashes. In spite of this heterogeneity of reasoning it has consistently been acknowledged, at times presumed, that dissident and spoiler groups emerging from splits are some of the most persistent users of political violence (Asal, Brown and Dalton, 2012; Della Porta, 2006; Darby, 2001; Tarrow, 1998; Hogan and Walker, 1989) but until recently there has been little scientific analysis carried out on why and how terrorist or insurgent groups split (Asal et al, 2012). This is unlike the analysis of splits in political, religious, economic and social movement organisations, where we there is a significant research history informing and guiding our understanding of organisational fragmentation (see for example Ansell, 2001; Balser, 1997; Burke Rochford Jnr, 1989; Singh, 1981; Hirschman, 1970). Therefore in order to gain a sufficient understanding about splits in terrorist groups we must broaden our scope to incorporate the analysis of non-violent, legal, organisations to inform our understanding of terrorist groups. By acknowledging that terrorist groups are not unique, and are actually quite similar to other human organisations, this opens up the opportunity of bolstering our understanding. Therefore what follows is a brief overview of our understanding of organisational splits, informed by researchers analysing both violent and non-violent organisations.

In order to truly understand the underlying rationale behind a split we must view it as part of an organisational process and evolution, rather than as a once off event. The internal factionalism that precedes a split predominantly grows from the call from certain sections of the organisation for a change in policies and/or practices (Burke Richford Jr, 1989). However, these factions may have their roots in previously long-standing cleavages between sub-groups (Ibid; Stark and Banbridge, 1985). For this reason analysts of splits must have clear understanding of the historical precursors, as they may prove informative in the search for a viable explanation. Similarly they must not stop their analysis at the point of split as the farreaching effects may prove more significant than the action itself. As was observed by Morrison (2014) the splits in the Irish republican movement may have actually laid the foundations for the eventual politicisation of the movement.

Balser describes factionalism as concerning groups belonging to the same organisation 'that come into conflicts as they pursue different goals, strategies and tactics, stemming from their diverging interests' (Balser, 1997, p.200). This description can prove to be significantly misleading as in the course of organisational factionalism the divided groups do not always differ on all three of the factors detailed by Balser. For example it is common that divided factions will be in agreement on the purposive goals they wish to pursue, however, have become factionalised in their views as to how best to achieve these goals. A clear example of this is evident in Khadka's analysis of factionalism in the Nepalese Communist movement where the movement was divided into two factions, both of which wished to abolish the existing monarchy, however, one wished to do so through democratic means and the other through people's agitation (Khadka, 1995). This illustrates the presence of agreement on goals but a split occurring due to a disagreement on how best to achieve these goals.

In his model of terrorist splitting Ethan Bueno de Mesquita (2008) argues that in the lead up to, and during, a split both the parent and splinter organisational leadership strive to maximise factional support. The model proposes that leaders are seeking to maximise the membership of their faction, without having preferences for the positions they adopt. In essence the model 
states that attracting physical numbers is necessary in the establishment of a successful terrorist organisation. This model, rightfully, distinguishes between those splits where the dissidents are more moderate than the parent party and those where they are more extreme. It states that a moderate faction is more likely to become enveloped within existing legitimate political organisations. In this model Bueno de Mesquita (2008) focuses purely on leadership positioning and the effect this can have on individual members' allegiance. However, in doing so it creates a myopic view of individual decision-making. It discounts the power of social interactions, personal relationships and trust working alongside ideological and leadership positioning. Individual allegiance may not always be tantamount to either understanding of the split or agreement with organisational positioning. For some personal factors, such as trust, may surpass ideological positions in allegiance decision-making (Morrison, 2016).

While the existence of factions and internal organisational disagreement may prove difficult for an organisation their presence do not always lead to organisational split. A split only occurs when one of these factions deems it necessary to leave the organisation to form a new group, and the two major predictors of the development of factionalism, and ultimately split, have been noted as being the 'heterogeneity of the social base and the doctrinal basis of authority' (Zald and Ash, 1966, pp.336-337). Consequently larger organisations may be deemed more susceptible to organisational factionalism and split as the larger the organisation the more heterogeneous it is likely to be (see Liebman, Sutton and Wuthnow, 1988).

Khadka's (1995) example of the Nepalese Communist movement once again illustrates this as it was observed that the larger the movement got the more internal feuds and factionalism proliferated. However, this should be only regarded as a prologue to our understanding of factionalism and splits, and we must question whether it is in fact the heterogeneity of a group's social base that can be the cause of a large group's factionalism. The very nature of an organisation dividing into factions displays a certain form of heterogeneity and therefore this notion of heterogeneous groups being more susceptible to splits is a tautology. There may be other factors at play within a split that may at first have been explained by heterogeneity. Each case of factionalism or split must be taken on its own merits and they must be analysed as to why and how each individual case occurred. For example what may be regarded as the result of heterogeneity in one case may be the result of a clash of personalities in another (Kaur, 1999). Therefore while the theoretical proposals of Zald and Ash (1966) and others may prove useful as guidelines, a guideline on what can be expected is all that they can really be. They must not be treated as true for each split until it has been applied and tested against the individual case.

Within the analysis of ethnopolitical organisations in the Middle-East it has similarly been supported that organisational and leadership makeup and structure can play a role in the probability of split. From their large- $N$ analysis Asal and colleagues demonstrated the significance of organisational and leadership structure in the probability of organisational split. Their findings indicated that a competing leadership structure, especially when it is coupled with the employment of tactical violence, can expedite the eventual splintering of an organisation (Asal et al, 2012). This is contrary to previous studies of political parties which state that the presence of factions within an organisation can actually improve the ability of a party to both maintain their existence and thrive (See Park, 2001). Through their quantitative analysis Asal et al (2012) also note that the presence of an initial split in an insurgent movement significantly raises the likelihood of future splits. This therefore points to the necessity of understanding the reasoning behind and process of initial splits if one is to gain a holistic understanding of all future splits. This further emphasises that splits should not be analysed as stand-alone events but must be considered as part of the greater evolution of terrorist and insurgent organisations

\section{$\underline{\text { Splits and Organisational Survival }}$}


Splitting to Survive

\author{
"Whatever else organisations seek, they seek to survive."
}

(Wilson, J.Q., 1974, p.10)

Throughout the literature on organisational splits the act of schism is often times referred to as the result of the decline or failure of the organisation. While it may be true that the split can be illustrative of a declining organisation researchers have shown through that organisations can prosper in spite of split. Balser (1997) cites the examples of Earth First! and the American Federation of Labour as two cases of organisations who succeeded and developed positively in the aftermath of a split. This is in line with the proposal that fragmentation can provide a positive impact on a group and can prove to be a vital step in the group's survival and prosperity. Balser cites these findings as being supportive of Simmel's view that schism can be utilised by an organisation in order to deal with internal conflict and external threats (Simmel, 1955).

The inaccurate classification of organisational split as being the failure or decline of a group has been similarly present when one analyses the literature on the fragmentation of terrorist groups specifically. Prior to the recent advances in our understanding of terrorist splits, many researchers of non-state violent organisations paid superficial attention to splits. Terrorist groups were treated as homogenous unitary entities, perpetually working as one. For years the analysis was wrongfully placed within the 'end of terrorism' literature (see for example Jones and Libicki, 2008). This approach failed to acknowledge the full process of split, classifying it incorrectly. The occurrence of organisational split is not analogous to the end of terrorism or political violence, or the end of the terrorist group. Approaching the topic from the end of terrorism standpoint fails to acknowledge the variety of forms of split which have no relationship with expiration. By considering it with this notion of finality will invariably fail to appreciate the short and long-term effects, which the split may have. Therefore, it is more accurate to describe an organisational split as a mode of terrorist formation, or the end of an organisation as a unified political movement rather than as the end of terrorism (Morrison, 2014; Oots, 1989).

A history of analysis of non-violent organisational splits demonstrates the necessity not to stop the investigation at the point of split but also to assess the immediate and distant effects of the fragmentation. While previous researchers may have regarded splits in the same vein as the 'end of terrorism' it is now more widely appreciated that there is so much more to organisational divides. It is argued here that we need to turn the previous end of terrorism literature 'on its head', and argue that it can be more productive to analyse splits from the perspective of organisational survival. This is by no means the first publication to propose the utility of survival in order to gain a greater understanding of splits in terrorist organisations (see for example Crenshaw, 1985; Oots, 1989; Perkoski, 2015) and there is an even longer history of the promotion of survival to understand non-terrorist organisational fragmentation (see for example Zald and Ash, 1966; Balser, 1997; Sani and Reicher, 1999). However, it is proposed that this article is still necessary, as the organisational analysis of splits in terrorist groups has largely only addressed the role of survival in it's most basic form, solely of maintenance of a unified and numerically strong membership. In order to address the full effects of organisational survival we must take this a step further to understand the nuances surrounding 'survival.'

Political organisational theory highlights that the primary aim of any political organisation is survival. A group must first of all achieve, and maintain, survival before they can come close to achieving their intended 'public goods', whether this is the establishment of a caliphate or an independent Basque country. The attainment of the goal is contingent on maintenance of 


\section{Splitting to Survive}

the identity of the organisation (Firey, 1948). Therefore the minimal and immediate goal of every organisation must be survival (Crenshaw, 1985).

It has been stipulated that organisations will become more conservative in their strategies and tactics if the survival and maintenance is somehow challenged (Zald and Ash, 1966). This may prove to be a facet of the organisational approach that is the inverse in terrorist organisations. The reality for terrorist groups may be more in line with social-movement organisations. Zald and Ash (1966) stated that for social movements in times of competition for support there might be a shift in goals that may be towards the centre, but may also move the group more towards the extremes. In relation to terrorist organisations it is observed that in order to avoid the departure of significant sub-groups of an organisation a formerly moderate membership may at times have to radicalise their tactics and strategies (Crenshaw, 1985). Therefore at certain stages the terrorist actions may aid in the survival of this organisation (Schelling, 1991). This is a complex role for the organisation to play as if they strategically or tactically over radicalise they risk losing the more moderate membership and external support. However, if they are not radical enough the risk lies in losing the more radical elements of the membership and support. The example of the Real IRA's bombing of Omagh displays the over radicalisation of tactics, with detrimental effects for the survival of the organisation (see Morrison, 2014). The organisational approach therefore acknowledges the challenges faced by the leadership of a terrorist organisation to maintain the survival of the group (Crenshaw, 1985).

The cornerstone of any organisation's survival at the most basic level is the group's ability to recruit new members. If a group fails to recruit, retain, and regenerate membership the survival of the organisation is unfeasible (Oots, 1989). With respect to terrorist organisations in particular the issue of membership regeneration is critical. The nature of terrorism leads to a high turnover of membership for a number of different reasons, included among these are arrest, burnout (Ross and Gurr, 1989), and death. Therefore the organisation must be able to constantly recruit new members and regenerate a fluctuant membership in order to maintain their survival. The leadership concern for organisational maintenance and survival is dominant, especially when there is a change in membership sentiment and a growing lack of interest in the organisation (Zald and Ash, 1966), or a lessening in support for the direction that the organisation is taking. These issues come to the fore especially at a time of organisational change or strain, which can lead to organisational split.

When looking threats to the survival and maintenance researchers are often looking at external threats to the maintenance and survival of a group. Yet organisational fragmentation is an internal threat to the basic level of survival. It is proposed that in the internal factionalisation of the organisation in the lead-up to a split that both sides are aiming for a form of organisational survival. With the presence of two competing internal sub-groups it may seem counter-intuitive that the immediate goal of both factions would be the same, but yet are competing against each other, and hence a basic understanding of organisational survival would determine that the nature of a conflict puts this goal at risk. However, in the case of a conflict over an issue which is deemed threatening to organisational identity the notion of survival does not purely constitute the maintenance of the same membership and organisational set-up. For both sides in the conflict, those proposing change, as well as those opposing it, the immediate goal is proposed to be the survival of the organisation in a form they respect and recognise. It is therefore hypothesised that

\section{H1: The immediate goal of each sub-group at the time of split is organisational survival in a form, which they respect and recognise.}

It is the addendum of 'in a form which they respect and recognise' to the traditional survival hypothesis which more accurately describes the immediate goal of an organisation, especially at a time of split. Factions are not aiming for the survival of the organisation just for the sake 
Splitting to Survive

of survival. It is deemed that there is no point in remaining within the organisation if it was not at least deemed to be moving in the direction of the group they aspired to. Therefore if the survival of the organisation at a basic level of maintenance of a unified membership is stunting the desired progress of the leadership, or a rival sub-group, a split may prove beneficial in this regard as it rids the parent or breakaway organisation of the internal detractors deemed to be holding the organisation back (Balser, 1997). This benefits those wishing to change the strategic, tactic, or ideological trajectory of the group. It allows them the opportunity to hive off those 'ideologues' unwilling to compromise on their position and vision for the group. By relieving the organisation of this factional opposition it allows a greater opportunity to successfully implement the actions at the centre of the split, whether this is the politicisation or further militarisation of the group, or even the promotion of a specific individual or group to leadership positions. It has been noted that within a terrorist group it is important to achieve consensus rather than a majority in order to bring about change (Rapoport, 2004). However, with more considered reflection the maintenance of group solidarity can at times prove detrimental for organisational survival and advancement, and the hope for consensus can on occasion stifle the desired progress of either the parent or dissident leadership.

At times of extreme intra-organisational conflict and debate the leadership will often times feel that they have to compromise their position in order to accommodate and retain the membership of some of their detractors, and therefore surrender their vision for the organisation. Therefore this can severely interfere with the organisation's pursuit of the specified public good. If it comes to the stage where they believe that they are over compromising in order to appease their internal detractors a split, or a minimal 'hiving off' of detractors believed to be holding back or disrupting the organisation, may be in the best interests of the leadership and the progress of the group. If nominal group solidarity is maintained for too long in such an environment the leadership is in danger of losing their position of power within the organisation or maybe maintaining the existence of a group whose aims, strategies and tactics they do not fully ascribe to. Therefore the immediate aim for the leadership should not be purely considered as the survival of the organisation, but the survival of the organisation in a form they ascribe to, applying the strategies, tactics and purposive aims that they stand by. At a time of extreme intra-organisational conflict and compromise, for the sake of survival the organisation can often times threaten to change to an unrecognisable state in comparison to the aspirations of the leadership. Alternatively if the leadership is unable to achieve the changes they deem necessary within the organisation they may reconcile if the organisation is deemed to be moving in the direction of their desired change. The type of change or debate that has the potential of causing internal division within an organisation is evidently a change that is viewed as highly significant by at least one section of the membership. Therefore it is at times necessary for the leadership to be patient in bringing about these changes and acknowledge that it may be a slow process to satisfy a significant proportion of the membership that the proposals are to the benefit of the organisation. If these changes are particularly dramatic or rapid they could lead to the defection of those who related to the original model (Della Porta, 2009, p.76). However, if the introduction of the change is gradual a number of these potential defectors may be convinced of the benefit of the change with only those most extreme detractors splitting. This form of split, or schism, has the most negligible effect on the group, its organisational structure, and evolution.

Groups are more likely to be at a numerical advantage if the pre-split factionalisation is based around a single strategic, personal or ideological disagreement. Being divided multidimensionally across a multitude of disagreements, or even absent of a single disagreement, tends to be disadvantageous to the ultimate physical survival of the organisation (Perkoski, 2015). If the parent, or dissident, leadership ultimately wishes to make multiple changes it will be more conducive to their survival to introduce these gradually. It is this gradualism which allows them a better opportunity of bringing the majority of the 
Splitting to Survive

organisational membership with them, and it will only be those deemed to be disruptive and adverse to change who will leave the group at a time of split. This suggests that the more focused the reasoning of the split the less dramatic the divide will be. This is supported by the comparison between the 1969 split in the Irish Republican Movement where the leadership tried to changed 'too much too soon' in their politicisation efforts leading to the formation of the dissident grouping which would become the Provisional IRA. When compared to the gradual politicisation of the Provisionals themselves from the 1980s on where the leadership only changed one step at a time, thus maintaining the majority of their membership and support and only losing those unwilling to compromise at the times of the two splits in $1986^{1}$ and $1997^{2}$ (see Morrison, 2014; Perkoski, 2015).

A similar argument can be put across for the internal detractors. If they believe that they are members of an organisation whose direction they no longer agree with or ascribe to there are three options available to them loyalty, voice and exit (Hirschmann, 1970). If their loyalty to the organisation outweighs their aversion to the direction of the movement they will carry on as members and remain silent about their concerns. However, if they wish to remain in the organisation but change the direction, aims or strategies of the group they will voice their concerns internally and try and bring about the changes they believe necessary. If the application of the tactic of voice fails to bring about the change(s) they wish the final option is that of exit. Members will only exit when the form and direction that the organisation has taken outweighs any loyalty that they have to the organisation and/or the leadership. Their exit can take three distinct forms. They can exit the organisation and cease all organisational participation. They can exit and join a rival organisation. The final option is that they can exit and set up a splinter organisation developed in a way supportive of their beliefs. Therefore the immediate aim for these detractors, and the leadership, is not purely the survival of the group but the survival of an organisation which they consider worthwhile and whose aims, tactics and strategies they believe in.

Every human organisation can experience intra-organisational conflicts. However, not all of these conflicts result in fragmentation. Therefore in order to understand organisational schism it is necessary to understand if there is a specific form of conflict that precedes split. Sani and Reicher (1999) propose that splits will only take place when the issue at the centre of the conflict is deemed to be threatening to the organisational identity by at least one of the subgroups involved. The heterogeneity of groups results in the organisational identity being perceived differently by the diverse members and sub-groups. Therefore the issue of perception is central to the second organisational hypothesis, which states:

\section{H2: That the conflict at the centre of the split is, for at least one of the sub-groups, threatening to the organisational identity.}

Hirschman (1970) outlined in relation to political organisations that at a time of intraorganisational factionalism the sub-group who are less 'tied' to their position are likely to gain more support than the sub-group who is unwilling to modify their position. During a significantly divisive conflict where there are two groups taking diametrically opposite positions with a number of members undecided on their position if one of the sub-groups is willing to move their position closer to the 'centre' they are more likely to gain the support of the undecided members than a sub-group who are firm in their position. Therefore in the aftermath of a split the sub-group more willing to compromise is expected to gain the larger support. However, if both groups are willing to compromise the split will be avoided.

\section{H3: The sub-group most willing to make compromises is the one most likely to be successful in attracting a wider membership and support in the aftermath of a split.}

\footnotetext{
${ }^{1}$ Forming the Continuity IRA

${ }^{2}$ Forming the Real IRA
} 
Splitting to Survive

The sub-group most willing to compromise weakens the 'push' factors away from them while simultaneously weakening the 'pull' factors of their rivals (Horgan, 2006). Invariably in splits it is the sub-group most 'tied down' to their strategic and ideological positioning which was the numerically weaker grouping in the aftermath of split, but the most ideological, strategically or tactically homogenous. Resultantly if there is one group in the pre-split factionalisation of the organisation who are unwilling to compromise they will be the ones most negatively affected in relation to numerical membership. If they are only willing to accept a perfect, or idealised, identity for the group they are more likely to lose out to a rival faction willing to compromise on their position.

Similar to times of tactical and strategic change the survival of the organisation is threatened with the presence of rival organisations. These rival organisations may come in the form of rival terrorist groups, or non-violent political organisations. Their presence leads to competition between the groups for membership and support. At times of competition the leadership must convince their membership and supporters to stay with their organisation as opposed to joining the alternative. The issue of competition from rival organisations becomes especially pertinent in the aftermath of a split, as a split by definition results in the development of a new breakaway organisation with similar goals and ambitions to the parent organisation. As has been detailed above at this time of competition, with the risk of losing members, the leadership may radicalise their tactics and strategies in order to maintain the survival of the organisation.

For an undesignated period of time after a split there is a higher consensus and consistency internally within the organisation, be it the parent organisation or the dissident group, and therefore maintenance can take a back seat to the development and evolution of the organisation and its goals. This time period of consensus can be quite short especially if the split results in the drawn out competition for membership and support. This is especially the case if there is a near even split in personnel. In such circumstances the competition for membership and support can be heightened as both groups and leaderships are evenly matched in strength and appeal. However, if the parent organisation's leadership can successfully isolate the defectors and keep their numbers and support small they will be in a stronger position to move forward with the development of the organisation than prior to the split. Therefore the aim of both leaderships, of the splinter and parent organisations, at a time of split must be to retain or gain the support of as many of those members and supporters occupying the middle ground between the two factions, while also retaining the support in their own specific sectors. This is not to purely maintain the survival of the organisation but to maintain the survival of an organisation in a form, or as close to a form as possible, which they believe in (see Morrison 2014).

\section{Conclusion}

In order to gain as complete an understanding of terrorism, and terrorists, it is vital that we consider not only the violent but also the non-violent activities of the group. While it is terrorist violence which draws us to analyse these groups, the acts of violence are peaks preceding much more frequent troughs of non-violence (Morrison, 2013). Within the troughs of non-violence comes the occurrence of organisational splits. The impact, and significance, of this organisational change has been demonstrated throughout this article. It has presented the argument that in order to gain a comprehensive understanding of terrorist organisations, and their evolution, that it is necessary to gain an understanding of any organisational shifts, especially with respect to splits and schisms. The article presents the initially counter-intuitive viewpoint that an appreciation of the permanent quest for organisational survival will give us a great insight into the process of organisational splits. By analysing splits through the lens of organisational survival it allows analysts to assess what the true effects of cleavage may be on the group. This is in stark contrast to the traditional 'end of terrorism' analysis of terrorism. 
Splitting to Survive

The article adapts the survival hypothesis, to acknowledge that organisations are not just aspiring to the maintenance of a fully intact organisation. It is proposed that the survival hypothesis is more accurate when one recognises that organisations are not just aiming for nominal survival, but the survival of the organisation in a form that they both respect and recognise. It is the motivation to reach this form of survival that may lead some factions to move away from the parent organisation, if they no longer respect or recognise the strategy, tactics, personnel or direction of the movement. Likewise it may at times be beneficial for the parent leadership, aspiring for this form of survival, to have a minor split in the movement if there are detractors hampering their vision for the evolution of the organisation. Developing on from this it is also proposed that the conflict at the centre of an organisational split must be perceived as threatening to the organisational identity for at least one of the sub-groups. If it were not then they would not be willing to take the dramatic step of dividing the organisation. However, for those who are unwilling to make compromises with respect to the conflict they will be least likely in attracting a wider membership and support in the aftermath of split. Their intransigence may provide them with their idealised perception of the organisation. However, it may in turn deplete their potential recruitment powers significantly, when in competition with former comrades willing to compromise.

The approach to organisational splintering proposed in this article is applicable to a variety of forms of human organisations, from political parties to organised criminal groups. By applying it to terrorist groups it allows one to take a step back from headline grabbing nature of terrorist violence, and gain an understanding of the organisational nature and evolution of these groups. It is only with this understanding that we can begin to counter the perpetrators of terrorism. An understanding of this organisational evolution can give us an insight into how they may accentuate their violence, or perhaps even politicise. The organisational approach taken here should be a tool used in our attempts to get closer to this level of understanding.

Future research needs to be carried out to assess similar themes including, but not exclusively, the birth, and demise, of organisational coalitions, and the consequences of split avoidance. This research can assess the role which survival plays in these circumstances, while simultaneously addressing the consequences that this may have on the frequency, or form, that the terrorist violence may take. However, before this future research takes place it is important that the hypotheses proposed in the present article are appropriately tested. It is proposed here that a quantitative database of splits in terrorist groups is developed, and analysed. This can be supplemented by the analysis of relevant organisational statements, terrorist autobiographies, and/or primary source interviews. It is vital that the present article is not considered as the final word on organisational splits and survival. If we are to advance our understanding the thesis proposed must be critically analysed and tested. In its current form it must only be considered as an introduction to these themes. 
Splitting to Survive

\section{References}

Abi-Habib, M. (2015). "Splits in Islamic State Emerge as its Ranks Expand." The Wall Street Journal. Available online http://www.wsj.com/articles/islamic-state-feels-growing-pains1425903933 (Accessed July 25th, 2016)

Ansell, C.K. (2001). Schism and Solidarity in Social Movements: The Politics of Labor in the French Third Republic. Cambridge: Cambridge University Press.

Asal, V., Brown, M., and Dalton, A. (2012) 'Why Split? Organizational Splits among Ethnopolitical Organizations in the Middle East.' Journal of Conflict Resolution, 56(1), pp.94-117

Balser, D.B (1997) 'The Impact of Environmental Factors on Factionalism and Schism in Social Movement Organisations.' Social Forces, 76(1), 199-228

Bloom, M. (2005). Dying to Kill: The Allure of Suicide Terror. New York: Columbia University Press.

Bueno de Mesquita, E. (2008) 'Terrorist Factions.' Quarterly Journal of Political Science, 3, $399-418$.

Burke Rochford Jr. E. (1989). Factionalism, Group Defection, and Schism in the Hare Krishna Movement. Journal for the Scientific Study of Religion, 28(2), pp.162-179.

Byman, D. (2016). "ISIS Goes Global: Fight the Islamic State by Targeting Its Affiliates." Foreign Affairs. 95.

Coghlan, T. and Evans, M. (2016). "Syrian Rebel Group Cuts Ties With Al-Qaeda." The Times. Available Online http://www.thetimes.co.uk/article/syrian-rebel-group-cuts-tieswith-al-qaeda-d83b9dggw (Accessed July 25th, 2016)

Cunningham, K.G. (2013a). 'Actor Fragmentation and Civil War Bargaining: How Internal Divisions Generate Civil Conflict.' American Journal of Political Science, 57(3), pp.659672

Cunningham, K. G. (2013b). 'Actor Fragmentation and Conflict Processes.' The Political Science of Syria's War, POMEPS Briefings (22), pp.34-36.

Cunningham, K.G., Bakke, K.M. and Seymour, L.J.M (2012). 'Shirts Today, Skins Tomorrow: Dual Contests and the Effects of Fragmentation in Self-Determination Disputes.' Journal of Conflict Resolution, 56(1), pp.67-93

Crenshaw, M. (2010), "Mapping terrorist organizations." Unpublished working paper

Crenshaw, M. (1985). An Organisational Approach to the Analysis of Political Terrorism. Orbis. Pp.465-489.

Darby, J. (2001). The Effects of Violence on Peace Processes. Washington DC: United States Institute of Peace Press

Della Porta, D. (2006). Social Movements, Political Violence, and The State: A Comparative Analysis of Italy and Germany. Cambridge: Cambridge University Press. 
Splitting to Survive

Della Porta, D. (2009). Leaving Underground Organisations: A Sociological Analysis of the Italian Case. In Bjorgo, T. and Horgan, J. (Eds.) (2009). Leaving Terrorism Behind: Individual and Collective Disengagement. London: Routledge. pp.66-87.

Driscoll, J. (2012). Commitment Problems or Bidding Wars? Rebel Fragmentation as Peace Building. Journal of Conflict Resolution, 56(1), pp.118-149.

Findley, M. and Rudloff, P (2012). Combatant Fragmentation and the Dynamics of Civil War. British Journal of Political Science, 42, pp.879-901

Firey, W. (1948). Informal Organisation and the Theory of Schism. American Sociological Review. 13(1). Pp.15-24.

Hafez, M.M (2007). Suicide Bombers in Iraq: The Strategy and Ideology of Martyrdom. Washington, D.C.: United States Institute of Peace Press, pp.243-249

Hirschman, A.O. (1970). Exit, Voice, and Loyalty: Responses to Decline in Firms, Organisations, and States. Cambridge, Massachusetts: Harvard University Press.

Hogan, G. and Walker, C. (1989). Political Violence and the Law in Ireland. Manchester: Manchester University Press.

Horgan, J. (2006). Disengaging from Terrorism. Jane’s Intelligence Review. (pp.34-37).

Jones, S.G. and Libicki, M.C. (2008). How Terrorist Groups End: Lessons for Countering al Qa 'ida. Pittsburgh: Rand Corporation.

Kaur, K. (1999). Akali Dal in Punjab Politics: Splits and Mergers. New Dehli: Deep and Deep Publications

Khadka, N. (1995). Factionalism in the Communist Movement in Nepal. Pacific Affairs, 68(1), pp.55-76.

Liebman, R.C., Sutton, J.R. and Wuthnow, R. (1988). Exploring the Social Sources of Denominationalism: Schisms in American Protestant Denominations, 1890-1980. American Sociological Review, 53(3), 343-352.

Morrison, J.F. (2013). "The Psychology of Terrorism: Current Understanding and Vital Next Steps. In The McGraw-Hill Homeland Security Handbook, D. Kamien (ed.).New York: McGraw-Hill

Morrison, J.F. (2014). The Origins and Rise of Dissident Irish Republicanism: The Role and Impact of Organizational Splits. New York: Bloomsbury Publishing

Morrison, J.F. (2016). "Trust in me: Allegiance choices in a post-split terrorist movement." Aggression and Violent Behavior 28, 47-56.

Obama, B. (1/28/2014). 2014 State of the Union Address.

Oots, K.L. (1989).Organisational Perspectives on the Formation and Disintegration of Terrorist Groups. Terrorism, 12, pp.139-152. 
Splitting to Survive

Rapoport, D.C. (2004). Series Editor's Preface. In Bowyer Bell, J. (2004). The IRA 19682000: Analysis of a Secret Army. London: Frank Cass. P.x

Ross, J.I. and Gurr, T.R. (1989). Why Terrorism Subsides: A Comparative Study of Canada and the United States. Comparative Politics, 21(4), pp.405-426.

Park, C.H. (2001). "Factional Dynamics in Japan's LDP since Political Reform. Continuity and Change." Asian Survey 41(3), 428-461.

Pearlman, W. (2013). 'Understanding Fragmentation in the Syrian Revolt.' The Political Science of Syria's War, POMEPS Briefings (22), pp.40-42

Pearlman, W. and Cunningham, K.G. (2012). 'Nonstate Actors, Fragmentation, and Conflict Processes.' Journal of Conflict Resolution, 56(1), pp.3-15

Perkoski, E. J. (2015). Organizational Fragmentation and the Trajectory of Militant Splinter Groups. Doctoral Dissertation, University of Pennsylvania

Sani, F. and Reicher, S. (1999). Identity, Argument and Schism: Two Longitudinal Studies of the Split in the Church of England over the Ordination of Women to the Priesthood. Group Processes and Intergroup Relations, 2(3), pp.279-300.

Schelling, T.C. (1991). What Purpose can "International Terrorism" serve? In Frey, R.G. and Morris, C.W. (Eds.) (1991) Violence, Terrorism, and Justice. Pp.18-32. Cambridge: Cambridge University

Schiller, D.S. (1987). A Battlegroup Divided: The Palestinian Fedayeen. In Rapoport, D.C. (Ed.) (2001). Inside Terrorist Organisations. (pp.90-108). London: Frank Cass.

Simmel, G. (1955). "Conflict." Free Press. Cited in Balser, D.B. (1997). The Impact of Environmental Factors on Factionalism and Schism in Social Movement Organisations. Social Forces, 76(1). Pp.199-228.

Singh, M.P. (1981). Split in the Predominant Party: The Indian National Congress in 1969. New Delhi: Shakti Malik Abinav Publications

Stark, R. and Banbridge, W. S. (1985). The Future of Religion: Secularizations, Revival, and Cult Formation. Berkeley, University of California Press.

Tarrow, S. (1998). Power in Movements. Cambridge: Cambridge University Press.

United States Institute for Peace (1999). How Terrorism End Special Report. Washington DC: United States Institute for Peace.

Weinberg and Richardson (2004). Conflict Theory and the Trajectory of Terrorist Campaigns in Western Europe. In Silke, A. (2004). Research on Terrorism: Trends, Achievements and Failures, (pp.138-160). London: Frank Cass.

Zald, M.N. and Ash, R. (1966). Social Movement Organisations: Growth, Decay and Change. Social Forces, 44(3). Pp.327-341 
Splitting to Survive

1
2
3
4

5

6

7

8

9

10

11

12

13

14

15

16

17

18

19

20

21

22

23

24

25

26

27

28

29

30

31

32

33

34

35

36

37

38

39

40

41

42

43

44

45

46

47

48

49

50

51

52

53

54

55

56

57

58

59

60 